\title{
Artigos
}

\section{A ressignificação da deficiência pela literatura: os impactos do Laboratório de Humanidades em mães de pessoas com deficiência}

The reframing of disability through literature: the impacts of the Laboratory of Humanities on mothers of people with disabilities (abstract: p. 17)

La resignificación de la discapacidad por la literatura: los impactos del Laboratorio de Humanidades en madres de personas con discapacidad (resumen: p. 17)

\author{
Ricardo Mituti Junior ${ }^{(a)}$ \\ <ricardo.mituti@unifesp.br> \\ Simeão Donizeti Sass ${ }^{(b)}$ \\ <sass@unifesp.br> (D) \\ Dante Marcello Claramonte Gallian ${ }^{(\mathrm{c})}$ \\ <dante.marcello@unifesp.br> iD
}

\author{
(a) Pós-Graduando do Programa \\ de Saúde Coletiva (Mestrado), \\ Departamento de Medicina \\ Preventiva, Escola Paulista \\ de Medicina, Universidade \\ Federal de Paulo (Unifesp). \\ Rua Botucatu, $740,4^{\circ}$ Andar \\ Sala 404, Vila Clementino. São \\ Paulo, SP, Brasil. 04023-062. \\ (b, c) Centro de História e Filosofia \\ das Ciências da Saúde, \\ Unifesp. São Paulo, SP, Brasil.
}

Este estudo tem como objetivo demonstrar os impactos da literatura em mães de pessoas com deficiência, no que concerne à ressignificação da condição de "mães especiais", por meio de participação na atividade Laboratório de Humanidades (LabHum), do Centro de História e Filosofia das Ciências da Saúde da Universidade Federal de São Paulo, Brasil, cujos propósitos são despertar afetos e sentimentos e fomentar a humanização pela discussão coletiva de temas existenciais suscitados nos clássicos da literatura universal. 0 estudo foi desenvolvido sob três metodologias qualitativas após leitura individualizada da fábula "Um apólogo", de Machado de Assis: do próprio LabHum, História Oral de Vida e Observação Participante. Os resultados indicam transformações positivas de perspectivas e reelaboração de valores humanísticos acerca do papel que essas mulheres cumprem como cidadãs que buscam ampliar o debate sobre a inclusão de pessoas com deficiência na sociedade.

Palavras-chave: Deficiência. Humanização. Laboratório de Humanidades. Literatura. 


\section{Introdução}

A Classificação Internacional de Funcionalidade, Incapacidade e Saúde (CIF), da Organização Mundial da Saúde (OMS), define deficiências como "problemas nas funçôes ou nas estruturas do corpo como um desvio significativo ou uma perda”. Elas "correspondem a um desvio dos padróes populacionais geralmente aceitos no estado biomédico do corpo e das suas funçôes”, podendo ser "temporárias ou permanentes; progressivas, regressivas ou estáveis; intermitentes ou contínuas"1.

O termo "deficiência" origina-se do latim deficientia, que significa falta, mas também enfraquecimento e abandono. E se nas áreas da Saúde a deficiência representa um desvio importante ou uma perda de funçóes, sejam físicas ou intelectuais, em âmbito social o significado extravasa os limites do vernáculo e se aproxima de sua etimologia.

No livro “O que é deficiência”, Débora Diniz escreve que, antes objeto

[...] De um campo estritamente biomédico, confinado aos saberes médicos, psicológicos e de reabilitação, a deficiência passou a ser também um campo das humanidades ${ }^{2}$. (p. 9)

Explica a autora que a referida ampliação de perspectiva, classificada como "guinada acadêmica”, teve origem nos Estados Unidos e no Reino Unido na década de 1970, quando se criaram novos paradigmas acerca da deficiência, que, hoje,

[...] não é mais uma simples expressão de uma lesão que impõe restrições à participação social de uma pessoa; deficiência é um conceito complexo, que reconhece o corpo com lesão, mas que também denuncia a estrutura social que oprime a pessoa deficiente ${ }^{2}$. (p. 9-10)

De acordo com estimativa da Organização das Naçóes Unidas (ONU), uma em cada cinco pessoas em todo o mundo sofre de algum tipo de deficiência. Em números absolutos, é quase 1,5 bilhão de pessoas.

No Brasil, o Censo Demográfico de 2010 indicava que 45,6 milhões de pessoas - ou quase $24 \%$ da população àquela época - declaravam ter ao menos um tipo de deficiência. Em 2018, o Instituto Brasileiro de Geografia e Estatística (IBGE), responsável pelo censo, emitiu nota técnica de releitura analítica dos referidos dados a partir da adoção completa de orientação do Grupo de Washington de Estatísticas sobre a Deficiência (GW), vinculado à Comissão de Estatística da ONU. A revisão, baseada nesse novo critério para margem de corte, reduziu o número de pessoas com deficiência no país para 12,7 milhôes - ou 6,7\% da população. Esse total se aproxima dos 12,4 milhôes de pessoas com deficiência - ou 6,2\% da população - obtidos pela Pesquisa Nacional de Saúde (PNS) 2013, também feita pelo IBGE.

Embora a Convenção Internacional sobre os Direitos das Pessoas com Deficiência, aprovada pela Assembleia Geral das Nações Unidas em 13 de dezembro de 2006 e promulgada pelo Brasil em 25 de agosto de 2009, garanta às pessoas com deficiência o mesmo tratamento que a sociedade dispensa aos demais cidadãos, o que se observa é que 
quase $80 \%$ dos 168 países signatários ainda não cumprem as metas de garantir direitos civis iguais, direito à saúde, à educação e ao trabalho à população com deficiência ${ }^{3}$.

Não bastasse a carência de políticas públicas eficazes para a real inclusão das pessoas com deficiência na sociedade, em seus diversos campos, a problemática da exclusão estende-se em parte aos familiares e/ou responsáveis. E isso porque eles também tendem a se tornar pessoas com necessidades específicas, carentes de orientação e de acesso a grupos de apoio. "Na verdade, são eles que intermediarão a integração ou inclusão de seus filhos junto à comunidade” (p. 53).

No que concerne à atuação da família nesse processo de inclusão, a literatura mostra que

[...] a presença de uma pessoa deficiente na casa [...] exigirá, de cada membro da família, redefinição de papéis e mudança [...]. Haverá sempre necessidades excepcionais - de tempo, reestrutura familiar, mudanças de atitudes e valores e novos estilos de vida 5 . (p. 86)

Vieira $e t a l .{ }^{6}$, sendo mais específicos, demonstram que

[...] as mães de crianças com paralisia cerebral, em especial, passam por diversas situações, como alterações na vida profissional e financeira, por exemplo; [...] é reduzido o tempo livre, em virtude da sobrecarga de cuidados prestados à criança, como vesti-las, alimentá-las, higienizá-las, acompanhá-las aos tratamentos e consultas; também há sentimentos de culpa e isolamento, reduzindo seus contatos sociais e culturais; além disso, há limites sociais e psicológicos, sendo as atitudes da sociedade em relação às pessoas com deficiência mental, geralmente, negativas ${ }^{6}$. (p. 58)

Referindo-se às genitoras, não é incomum que elas se vejam obrigadas a abdicar de seus anseios e projetos, nos âmbitos pessoal e profissional, para se dedicarem aos cuidados intrínsecos à realidade limitada de seus descendentes.

Tal situação reforça uma necessidade premente: essas mulheres terão de adquirir conhecimentos especiais e a compreensão da dinâmica do comportamento humano, dos fenômenos de transformação e da psicologia da vida cotidiana. Somente pela expansão do seu conhecimento e dos sentimentos que trazem consigo, a esperança, elas serão capazes de alcançar a ação criativa ${ }^{5}$ (p. 93) para enfrentamento de um rotina reinventada e adaptada.

Considerando-se, portanto, que as famílias de pessoas com deficiência precisam de assistência aos seus, ao mesmo tempo em que buscam alguma forma de acolhimento para tal enfrentamento, espera-se que iniciativas que cumpram essas funçóes tenham relevância e impacto positivo na vida dos familiares.

Nesse sentido, atividades humanísticas podem aprimorar neles essa sensação de acolhimento e contribuir para que eventuais entraves afetivos, psicossociais, culturais e profissionais, originados com a deficiência de seus descendentes, sejam atenuados ou experimentados sob uma perspectiva menos desalentadora e, eventualmente, mais otimista. 
É nesse ponto que se observa uma aproximação entre tal possibilidade e o conceito de humanização formulado pelo filósofo francês Charles-Louis de Secondat, conhecido como Montesquieu, em "O gosto 7", de "ampliação da esfera da presença do ser”, em uma tradução do pensador Teixeira Coelho ${ }^{8}$. E é nesse ponto, também, que dinâmicas, como o Laboratório de Humanidades (LabHum), do Centro de História e Filosofia das Ciências da Saúde da Universidade Federal de São Paulo (CeHFi-Unifesp), podem cumprir tal papel, colaborando para que realidades, como a ora apresentada, que se aproximam da despersonalização e da desumanização, sejam transformadas em oportunidades de reaproximação com o "eu interior”, desfigurado pelo estigma da deficiência em família.

\section{O Laboratório de Humanidades}

O LabHum é uma experiência de leitura e releitura compartilhada surgida em 2003, na Escola Paulista de Medicina da Universidade Federal de Paulo (EPM-Unifesp), cujos objetivos são despertar os afetos e sentimentos dos participantes e fomentar neles a humanização por meio da discussão coletiva de temas existenciais suscitados por clássicos da literatura universal - pilares da dinâmica.

E por que os clássicos, em detrimento das obras contemporâneas?

No livro "A Literatura como remédio - os clássicos e a saúde da alma” de 2017, Gallian, citando "Por que ler os clássicos”, de Ítalo Calvino, explica que

[...] um dos elementos que mais caracterizam uma obra clássica é justamente o de apresentar, de uma forma magistral, o "problema" do humano enquanto questão eterna e universal, para além das circunstâncias históricas e culturais. Assim, inevitavelmente, a leitura de um clássico suscitará o reconhecimento dessas questões essenciais da existência humana, despertando no leitor a curiosidade e o desejo de enfrentá-las ${ }^{9}$. (p. 175-6)

Assim sendo, como experiência humanística baseada no compartilhamento de reflexôes originadas em obras literárias - portanto, uma experiência estético-reflexiva -, o LabHum provoca nos participantes a elaboração e a expressão de afetos, sentimentos e ideias, em um verdadeiro processo de transformação em que se verifica a renovação de aspectos emocionais e a aquisição de uma nova consciência, mostrando-se dessa forma um potente meio de humanização ${ }^{10}$ (p. 13).

O experimento do LabHum ensina que a literatura e a narrativa literária, ao mobilizarem os afetos, surgem como um acontecimento estético - de aesthesis (despertar) -, no qual esse despertar afetivo desencadeia um intenso processo reflexivo, pelo mergulho e pelo encontro com questóes essenciais da existência humana trazidas pela literatura.

Werner Jaeger, no livro "Paideia: a formação do homem grego", citado por Gallian, na década de 1930, já dizia que 
[...] há no âmago das grandes obras alguma coisa que tem validade universal, e que, ao ser, de alguma maneira, reconhecida por quem as está fruindo, desencadeia uma força emocional capaz de mover os homens. Esta experiência não tem um sentido meramente sensível, mas de profundidade. Não se limita à dramatização exterior que torna a narração uma ação participada, mas penetra no espiritual, no que a pessoa tem de mais profundo. E, para os gregos, esta conversão espiritual, que provém da experiência estética e afeta a dimensão ética da pessoa, encerra o sentido mais profundo e completo da terapia. A psicogagia é a conversão que traz a cura, em sua dimensão mais ampla, envolvendo o espírito, a alma e o corpo'. (p. 200-1)

Contemporâneo de Jaeger, Henri Bergson, nessa mesma época, no ensaio "A percepção da mudança”, destacava o papel essencial desempenhado pelos escritores, considerados artistas das letras:

A arte visa nos mostrar, na natureza e no espírito, fora de nós e em nós, coisas que não impressionavam explicitamente nossos sentidos e nossa consciência. O poeta e o romancista divulgam o que estava em nós mas que ignorávamos porque faltava-nos palavras. [...] À medida que nos falam, aparecem-nos matizes de emoção que podiam estar representados em nós há muito tempo, mas que permaneciam invisíveis $[\ldots]^{11} \cdot($ p.155)

Convém destacar, também, o que diz Paul Ricouer, na trilogia "Tempo e narrativa" Para ele, a narrativa é uma mediadora da linguagem e da ação, tendo a qualidade de apreender a intensidade da experiência humana ao inscrevê-la em uma temporalidade.

Ainda de acordo com esse autor, a atividade narrativa confere ao homem a possibilidade de uma relação mais evidente com o tempo, a partir do momento em que garante a possibilidade de apreender a respeito de sua passagem, mas também de anunciá-la e compartilhá-la, relacionando assim os três grandes "instantes" da existência - passado, presente e futuro.

Também é de Ricouer a concepção de identidade trabalhada nessa investigação. Segundo ele, essa concepção é sempre narrativa, pois não há como compreendê-la sem que se recorra a uma narração. Da mesma maneira, cumpre papel de mediadora - como já mencionado -, haja vista constituir-se no encontro com o outro, permitindo que a pessoa se aproprie do mundo e se modifique, permanecendo nele.

Depreende-se, com isso, que as narrativas literárias, como expressóes artísticas, se revelam vigoroso meio de transformaçóes pessoais possíveis - e de humanização, por conseguinte, como "ampliação da esfera da presença do ser" - quando trabalhadas como instrumentos de despertamento e explicitação de afetos, em uma dinâmica coletiva, tendo em vista a possibilidade de reflexôes sobre vida e ressignificaçóes - pela perspectiva de temas suscitados nos livros, tal qual sugere o LabHum.

Como bem destaca Antoine Compagnon em seu "Literatura para quê?", a literatura, no papel de protagonista de tal experiência humanística, 
[...] permite acessar uma experiência sensível e um conhecimento moral que seria difícil, até mesmo impossível, de se adquirir nos tratados dos filósofos. Ela contribui, portanto, de maneira insubstituível, tanto para a ética prática como para a ética especulativa ${ }^{13}$. (p. 46)

Sobre o uso da literatura na construção de uma abordagem hermenêutica da relação saúde-doença, Caprara diz que

As obras literárias permitem abordar aspectos da vida humana, como o fato de saber lidar com as emoçôes, que são elementos constitutivos importantes especialmente na relação médico-paciente [...]

A comunicação médico-paciente pode ser aprendida como técnica, mas certamente a obra literária permite construir um contexto ético na qual a relação vai se desenvolvendo ${ }^{14}$. (p. 929)

\section{Metodologia}

A metodologia utilizada neste estudo foi a do LabHum, atividade do projeto regular de pesquisa Humanidades, Narrativas e Humanização em Saúde, do CeHFi-Unifesp, que conta com financiamento da Fapesp e congrega mais de uma dezena de pesquisadores no nível de iniciação científica, mestrado e doutorado dos programas de Saúde Coletiva e Ensino em Ciências da Saúde da EPM-Unifesp ${ }^{15}$.

Surgido com base em encontros com estudantes de graduação em Medicina, o LabHum busca promover a formação humanística e a humanização em saúde ${ }^{16}$.

A aplicação do LabHum se dá por meio de ciclos específicos por livros. Assim, um livro é igual a um ciclo.

Os ciclos regulares são constituídos por encontros semanais, de uma hora e trinta minutos de duração.

Espera-se que os participantes façam uma leitura prévia do livro que será trabalhado no ciclo, embora essa não seja uma atividade exclusiva de quem a cumpre.

No primeiro encontro, o coordenador da atividade conta a história do laboratório, explica os objetivos e a metodologia, menciona os efeitos possíveis e esclarece os fundamentos teóricos da vivência.

Concluída essa apresentação, tem início a dinâmica, quando os participantes são convidados a relatar suas Histórias de Leitura - a primeira etapa da metodologia. A eles cabe narrar a experiência pessoal de leitura da obra, com destaque aos afetos despertados, sentimentos percebidos, lembranças proporcionadas e possíveis questionamentos surgidos. 
Posteriormente às Histórias de Leitura, que fecham o primeiro encontro do LabHum, seguem os Itinerários de Discussão - a segunda etapa da metodologia. É quando costumam iniciar as reflexões em grupo acerca dos temas centrais da narrativa, levantados pelos participantes e registrados pelo coordenador da atividade na fase de Histórias de Leitura. O número de encontros de Itinerários de Discussão varia conforme a extensão da obra.

Ao final dos Itinerários de Discussão, os participantes vivenciam a terceira e última etapa da metodologia: as Histórias de Convivência.

Narradas pelos participantes em encontro único, essas histórias são uma síntese individual sobre a experiência de participação no Laboratório, oral ou escrita, que torna públicos os efeitos da vivência na vida e na personalidade de cada um.

Sendo bem-sucedida, a metodologia pode promover, ao término de sua aplicação, a revisão de valores, conceitos e opinióes acerca de temas caros à existência humana, concretizando-se, assim, o esperado processo de humanização.

Com relação às metodologias da investigação, foram utilizadas a da Observação Participante e a da História Oral de Vida.

A primeira implica, por parte do observador, conforme Valladares ${ }^{17}$, saber ver, escutar, utilizar todos os sentidos e fazer perguntas no momento adequado.

Ainda sobre Observação Participante, Fernandes ${ }^{18}$ diz que pressupõe o convívio, a comunicação e o intercâmbio de vivências, predominantemente por meio da utilização dos sentidos, entre o pesquisador, os participantes do estudo e o contexto das relações que circundam a todos - ou seja, é o estar, observar, participar e tomar notas enquanto as açôes acontecem.

Os dados da pesquisa foram coletados por meio dos seguintes procedimentos: gravação integral em áudio dos encontros, de todos os ciclos, pelo coordenador, com o gravador existente em telefone celular, e anotaçóes de campo, também pelo condutor do LabHum.

Após a realização dos ciclos de LabHum, foram realizadas entrevistas com as participantes segundo a técnica da História Oral de $\mathrm{Vida}^{19}$, quais sejam: gravação digital da entrevista e sua posterior transcrição, textualização, transcriação, conferência e validação.

Conforme os autores, transcrição é a passagem rigorosa da gravação para o texto escrito. Já na textualização, as perguntas são transportadas e agregadas às respostas, e os depoimentos são reorganizados em primeira pessoa. Na transcriação, o pesquisador intervém mais ativamente, procurando incluir no texto o sentimento demonstrado durante a narrativa da história. Tal versão transcriada é, posteriormente, submetida à avaliação, à conferência e à autorização do autor da narrativa, para validação e legitimação.

Após obtidos pelas metodologias supracitadas, os dados foram organizados e interpretados, também em âmbito qualitativo, por meio do processo de Imersão e Cristalização, cunhado por Miller e Crabtree e descrito por Borkan ${ }^{20}$.

Por meio de leituras consecutivas para poder vivenciar o texto, tal metodologia prevê ciclos de imersóes nas narrativas colhidas. A esses ciclos seguem as reflexões pelo pesquisador, denominadas, pelo autor, cristalizaçôes intuitivas. 
Por exigir envolvimento emocional e cognitivo, esse método de análise permite que o pesquisador vá além da interpretação manifesta para ver, ouvir e sentir os dados, de modo que tenha condições de isentar suas próprias opiniôes das descobertas e interpretações realizadas.

Uma vez efetuada essa primeira fase de interpretação das narrativas em uma perspectiva fenomenológica, foram definidos temas e categorias emergentes, posteriormente analisados à luz do referencial teórico pertinente, possibilitando a apresentação de consideraçôes e conclusôes que poderão nortear novas intervenções em contextos análogos e/ou pesquisas semelhantes.

Este estudo está aprovado pelo Comitê de Ética e Pesquisa da EPM-Unifesp, sob parecer número 3.618.860.

\section{Resultados e discussão}

O estudo ora apresentado foi feito com base na aplicação de dois ciclos do LabHum, em outubro e novembro de 2019, em dois grupos de dez mulheres, mães de pessoas com deficiência de oito a 16 anos de idade, assistidas por organização não governamental, convidadas a participar da atividade voluntariamente.

Para a realização de ambos os ciclos, foi escolhida a narrativa “Um apólogo”, do escritor brasileiro Machado de Assis.

A obra retrata a história de um diálogo fictício, permeado por alto nível de animosidade, entre uma agulha e um novelo de linha, cada qual valorizando excessivamente seu próprio trabalho como principal responsável pela confecção de um vestido, depreciando, para isso, o trabalho desempenhado por seu interlocutor.

Tal narrativa é uma fábula:

[...] narrativa curta, não raro identificada com o apólogo ou a parábola, em razão da moral, implícita ou explícita, que deve encerrar, e de sua estrutura dramática. No geral, é protagonizada por animais irracionais, cujo comportamento, preservando as características próprias, deixa transparecer uma alusão, via de regra satírica ou pedagógica, aos seres humanos ${ }^{21}$. (p. 184)

A opção pelo referido gênero literário deu-se pelo fato de ser ele de fácil linguagem e compreensão, acessível mesmo a quem não cultiva o hábito da leitura, e por conter, implícitas ou explícitas, mensagens e ensinamentos engrandecedores, capazes de impactar positivamente os pensamentos e atitudes de quem, por circunstâncias diversas, abdicou de si própria em prol da uma vida melhor para os filhos.

Os ciclos do LabHum da fábula machadiana aconteceram separadamente e tiveram quatro encontros com cada um dos grupos observados. Tais encontros foram realizados semanalmente, e, durante o período em questão, foram aplicadas as três fases da metodologia do LabHum. 
Para investigação do LabHum com apoio de bibliografia pertinente, recorreu-se aos seguintes autores: Amiralian ${ }^{22}$, que analisa quanto a percepção da deficiência do outro pode levar à consciência dos próprios limites e das próprias deficiências, além de também falar sobre os sentimentos, capacidades e incapacidades no processo de empatia de cuidadores em relação à pessoa com deficiência; Fédida ${ }^{23}$, por creditar à deficiência o ressurgimento de angústias e por lembrar a vulnerabilidade do ser humano; e $\mathrm{Miller}^{24}$, que orienta mães, em especial, a adotar determinadas práticas de controle do estresse para autopreservação e, por consequência, maior equilíbrio no trato com filhos com deficiências.

A experiência pretendia investigar os efeitos causados pelo debate de temas existenciais, suscitados por um clássico da literatura, em mães de pessoas com deficiência, partindo da premissa já mencionada de que a literatura amplia a capacidade de percepção das experiências e do mundo, de modo que pode contribuir para a ressignificação de sentimentos, valores e vivências.

Para o cumprimento desta proposta, a hipótese trabalhada foi a de que o contato com situaçôes adversas na narrativa literária poderia criar empatia e permitir às participantes da atividade o compartilhamento de experiências e impressóes acerca das dificuldades pessoais observadas diante das limitações impostas pela deficiência de seus descendentes, em âmbito familiar, ou de outros aspectos correlacionados a tal realidade em uma perspectiva social mais ampla.

Durante a aplicação dos ciclos, considerando-se os oito encontros realizados, 16 temas relativos a "Um apólogo" foram observados pelas voluntárias, ora listados conforme mencionados:

1. arrogância/prepotência;

2. orgulho;

3. vaidade;

4. autoestima;

5. maturidade;

6. humildade;

7. competitividade;

8. inveja;

9. alteridade;

10. aparências;

11. sinceridade;

12. adversidades;

13. reação a provocações;

14. empatia;

15. julgamento; e

16. gratidão/reconhecimento. 
Alguns desses temas foram aprofundados durante os encontros de Itinerários de Discussão - a segunda etapa da metodologia do LabHum -, em especial, e desdobraramse em percepçôes e manifestaçôes que permitiram relacionar o âmago do diálogo fictício entre os objetos, na narrativa machadiana, e a singularidade de aspectos da existência individual por elas retratada.

Essa relação entre narrativa e singularidade é, para Dilthey, consequência da compreensão, no contexto da hermenêutica, induzida pela literatura como meio de objetivação da subjetivação. Diz Dilthey:

A importância imensurável da literatura para nosso entendimento da vida espiritual e da história reside exatamente no ato de que a vida interior encontra somente na linguagem sua expressão completa, exaustiva e objetiva. Por isso, a arte de entender tem seu centro na exegese ou interpretação daquilo que foi preservado da existência humana pela tradição escrita ${ }^{25}$. (p. 367)

Nesse movimento de conexão entre narrativa e subjetividade, um dos temas suscitados durante os ciclos de LabHum foi o que consumiu mais tempo de reflexão e surgiu em ambos os grupos, ainda que sob perspectivas relativamente diferentes: a alteridade.

Em linhas gerais, as voluntárias de um dos grupos ativeram-se à importância do outro em suas próprias vidas e no trabalho coletivo em prol do que consideraram "um bem maior", como se manifestou uma delas, em detrimento de orgulho, vaidade e competitividade em busca de reconhecimento, seja próprio ou por terceiros, tal qual agulha e linha demonstram no decorrer do diálogo em "Um apólogo", partindo da desvalorização mútua como meio de supervalorização individual.

De volta ao método compreensivo de Dilthey, Sass explica que o posicionamento supracitado, como interpretação de uma vivência, ocorre quando essa interpretação se objetiva na expressão concreta:

É o espírito objetivado do ser humano que a compreensão visa decifrar. Só há compreensão por intermédio da expressão. E o sentido impresso na expressão surge da manifestação daquilo que foi vivenciado de algum modo. Interpreta-se, assim, sentidos e significados oriundos de experiências ${ }^{26}$. (p. 546)

Nesse sentido, baseadas em suas experiências subjetivas e na interpretação que fizeram da fábula, as participantes externaram opinióes e valores sobre a alteridade - e temas correlacionados - por meio de frases como: 
a. “É preciso enxergar o outro".

b. "Ninguém é mais do que ninguém".

c. "Precisamos um do outro para poder evoluir".

d. "A gente não é ninguém sozinho".

e. "Para tudo dependemos do outro, do nascimento até a morte".

f. "Qual é o lugar do outro?”.

g. "Às vezes a gente só vê nossas qualidades e não as dos outros. E todos têm defeitos e qualidades".

h. "Não devemos encarar tanto o defeito do outro como definitivo. Nem todas as pedras amontoadas são ruínas".

i. "É preciso respeitar a opinião do outro e saber se posicionar em relação ao outro".

j. "Aprendi a respeitar o olhar do outro".

k. "Por que apontar o dedo para o outro?".

1. "Devemos aprender a sentir orgulho da gente e do outro também. Afinal, a gente não é nada sem o outro”.

m. "Um aprende com o outro. Não devemos nos sobrepor ao outro".

n. "O outro não é culpado pelo meu problema”.

o. "Procuro me colocar no lugar do outro".

p. "Conviver é aprender a respeitar e aceitar o outro".

q. "Preciso tentar lidar com as diferenças de cada um".

r. "Não é fácil lidar com as diferenças das outras pessoas".

s. "Tenho de respeitar o momento do outro e o jeito do outro".

t. "A gente não é único; não consegue nada sozinho".

u. “Todos têm função importante na criação do produto final” [referindo-se ao vestido citado na narrativa].

v. "Cada um de nós tem suas próprias qualidades e sua missão individual, mas um depende do outro. Todas as qualidades somadas vão dar o resultado esperado”.

Em dissonância das reflexões centradas no tema ora exposto, mas em clara expressão de ressignificação de valor subjetivo relacionado à deficiência, motivada pela reflexão coletiva acerca da temática suscitada pela narrativa machadiana, uma das participantes declarou: "a maternidade especial é um aprendizado" e que "a gente precisa se amar primeiro [antes de amar o outro]", evidenciando, assim, que antes de um outro há um eu que carece ser percebido, respeitado e valorizado, qualquer que seja sua condição.

Sobre tal perspectiva relacional, entre o eu (representado pela mãe) e o tu (representado pelo outro por ela idealizado), para a construção da alteridade, Buber diz que 
Somente aquele que se volta para o outro homem enquanto tal e a ele se associa recebe neste outro o mundo. Somente o ser cuja alteridade, acolhida pelo meu ser, vive face a mim com toda a densidade da existência é que me traz a irradiação da eternidade. Somente quando duas pessoas dizem, uma à outra, com a totalidade dos seus seres: 'és tu!' é que se instala entre elas o Entre ${ }^{27}$. (p. 65)

\section{A deficiência pela perspectiva da alteridade}

Se a subjetividade das participantes de um grupo concentrou as reflexóes sobre alteridade em uma tentativa de equiparação de condiçóes entre as pessoas, sejam elas com deficiência ou não, ainda que pela perspectiva única e limitada da importância da coletividade na construção de uma realidade mais equitativa - em analogia ao vestido que seria confeccionado pela agulha e pela linha (e por outros personagens, secundários e/ou não mencionados) da fábula -, o segundo grupo aproximou-se da formulação de uma teoria, não cientificista, por meio do papel desempenhado pelas protagonistas $\mathrm{da}$ história e pelo diálogo travado por elas.

Em analogia ao trabalho de "abrir caminho" exercido pela agulha na narrativa, uma das participantes declarou que achava "legal" a agulha "sair abrindo caminho" para a linha coser o tecido que daria origem ao vestido. E prosseguiu seu raciocínio questionando: "Quantas vezes não abrimos caminhos para as pessoas, e o contrário também?”

Tal reflexão levou a uma constatação coletiva, com base em uma percepção subjetiva comum a todas as participantes, acerca da deficiência: embora ainda hoje famílias sofram consequências de uma visão estigmatizada do problema - e, conforme declarou uma delas, "há dificuldade de aceitar as pessoas como elas são" -, a sociedade, em uma perspectiva generalista, é mais inclusiva se comparada à de outras épocas. E isso só se deu, na opinião dessas mulheres, porque "muita gente abriu caminho para chegarmos até aqui", como disse outra participante, relembrando o papel da agulha no apólogo de Machado.

A apropriação de uma passagem da narrativa pelas participantes do LabHum, após tal constatação, levou a uma afirmação por outra das mães, que traduzia um afeto despertado em todo o grupo durante a dinâmica: "Na verdade, as mães e os filhos especiais de hoje são as agulhas das novas geraçôes, abrindo caminho para transformações sociais mais profundas, para a construção de uma nova sociedade”.

Tal opinião desencadeou duas outras manifestações congêneres, por outras duas participantes.

A primeira declarou que "ser agulha é uma honra, porque o importante é abrir caminho para os outros. Mas também não deixamos de ser linhas, seguindo pelo caminho aberto por outras agulhas". A segunda, por sua vez, admitiu que "o que eu quero ser na vida é agulha e abrir caminho para as pessoas".

No que concerne à ressignificação de perspectivas acerca da deficiência filial e $\mathrm{da}$ "maternidade especial" durante a atividade, ambas as questóes emergiram com frequência, estivesse ou não em debate o tema da alteridade. Possível foi notar, entretanto, que ora vinham à tona de modo subjetivo, ora surgiam com manifestaçóes quase didáticas acerca da problemática. 
Três dessas passagens, por participantes diferentes, merecem destaque:

1. Menção à não aprovação do termo "pessoas especiais" para pessoas com deficiência, sob o argumento de que "especiais não são as pessoas, mas suas necessidades" - no que tangia às reflexôes sobre o lugar do outro como pessoa com deficiência, em uma sociedade ainda não totalmente inclusiva.

2. O quão transformadora é a experiência de ter um filho com deficiência, tal qual declarou uma mãe, ao admitir que "eu me transformei depois da minha filha especial. E tenho orgulho da pessoa que sou hoje" - no que concernia a reflexóes sobre a temática do orgulho, em analogia à forma como esse sentimento foi explorado na narrativa machadiana, na perspectiva da agulha em relação à linha.

3. A forma como a sociedade percebe as “mães especiais". Segundo uma terceira voluntária, "a mãe especial sempre é julgada. Quando está ao lado do seu filho, é uma guerreira, uma pessoa boa. Agora, quando não está com o filho, que precisa dela, torna-se uma pessoa má e deixa de ser uma boa mãe” - no que tocava à questão do julgamento, abordado no apólogo pela perspectiva da linha, que acusava a agulha de fazer um trabalho "obscuro e ínfimo" na confecção do vestido.

Tais discursos evidenciam a exteriorização do eu dessas mulheres, em um contexto do que representam em relação ao outro e em virtude dele, fomentada pela apropriação de temáticas suscitadas pela literatura.

No que diz respeito à questão da alteridade nas passagens 2 e 3 acima mencionadas, Paul Ricouer explica que "A autodesignação do sujeito falante se produz em situações de interlocução nas quais a reflexividade se associa à alteridade $[. .$.$] ”28 (p. 111) e que "[...] a$ alteridade de outrem, como toda outra alteridade, se constitui em (in) mim e a partir de (aus) $\operatorname{mim}[\ldots]^{\prime 28}$ (p. 169).

Lévinas, por sua vez, ao analisar o papel do discurso e da linguagem nas suas formulações acerca dessa mesma temática, explica que

Por meio do discurso, a exterioridade se manifesta sem violência alguma e o eu se põe em relação a uma totalidade que, ultrapassando a existência subjetiva, realiza o encontro entre dois seres, um eu e um tu. No entanto, esse eu e esse tu que figuram no face a face do discurso são papéis exercidos no drama social, pois os interlocutores estão determinados por diferentes condições ${ }^{29} \cdot($ p. 45)

Contudo, se a obra literária fomentou o despertar dos afetos e a linguagem-discurso permitiu a expressão da alteridade pela percepção da presença do outro, naquilo que se pode denominar intersubjetividade, superar as barreiras sociais entre o eu e o tu interpostas pela deficiência só pôde ser considerada por essas mulheres uma realidade plausível por meio da relação constituída por esse encontro.

Se a percepção ora apresentada se deu pela perspectiva do reconhecimento da pessoa com deficiência e de sua mãe-cuidadora como outros corresponsáveis pela construção de uma aspirada nova ordem sociocultural, mais inclusiva e menos discriminatória, pode-se dizer, assim, que a fábula machadiana, inserida na perspectiva dos debates suscitados na dinâmica do LabHum, cumpriu importante papel de ressignificação de valores e reelaboração de anseios, tal qual se espera de uma experiência humanística. 


\section{Considerações finais}

O alto nível de subjetividade percebido durante as manifestaçôes verbalizadas das participantes dos ciclos de LabHum, aliado aos referenciais teóricos que norteiam a aplicação da metodologia, permite concluir que a atividade pode ser posicionada como instrumento fomentador de ressignificação de opiniôes, valores e conceitos como experiência de autoconhecimento e de conhecimento do outro.

Trata-se, como visto, de uma dinâmica de fato humanística, por impactar, por meio do despertamento pela arte, três dimensóes essenciais da existência: o afeto (que, na vivência do LabHum, nasce com a leitura individual da obra literária), a inteligência (manifesta nas reflexóes a propósito dos temas suscitados pela narrativa) e a vontade (explicitada na forma como os efeitos da vivência afetam o ethos de quem dela participa, conduzindo a um processo de humanização).

Em síntese, o LabHum toca o ético pelo estético - podendo, inclusive, remodelá-lo -, propiciando, sob o aspecto de experiência de encontro com o outro, o descortinar de novas perspectivas, capazes de promover transformaçóes nos âmbitos pessoal e coletivo, na vida privada e/ou profissional.

Tal qual afirma Compagnon em "Literatura para quê?", a dizer que "a literatura nos liberta de nossas maneiras convencionais de pensar a vida - a nossa e a dos outros"13 (p. 50) e que "seu poder emancipador [da literatura] [...] nos conduzirá por vezes a querer derrubar os ídolos e a mudar o mundo, mas sempre nos tornará simplesmente mais sensíveis e mais sábios, em uma palavra, melhores”13 (p. 501), a experiência do LabHum com mães de pessoas com deficiência contribuiu, efetivamente, para o surgimento de uma percepção mais humanizada e menos estigmatizada acerca da deficiência, dos impactos socioemocionais por ela - e a elas impostos e do próprio papel que desempenham na sociedade, como corresponsáveis pelo fomento de açóes, práticas, medidas, estratégias e políticas de inclusão, capazes de situar seus descendentes não mais em condição de exceção, passíveis de tratamento diferenciado, mas como integrantes de uma nova realidade, equânime, não discriminatória e mais humanizada. 


\section{Contribuições dos autores}

Todos os autores participaram ativamente de todas as etapas de elaboração do manuscrito.

\section{Financiamento}

Este artigo é resultado de pesquisa em que um dos autores é beneficiado por bolsa concedida pela Coordenação de Aperfeiçoamento de Pessoal de Nível Superior - Capes.

\section{Conflito de interesse}

Os autores não têm conflito de interesse a declarar.

\section{Direitos autorais}

Este artigo está licenciado sob a Licença Internacional Creative Commons 4.0, tipo BY (https://creativecommons.org/licenses/by/4.0/deed.pt_BR).

\section{(cc) BY}

\section{Editora}

Rosana Teresa Onocko Campos

Editora associada

Simone Mainieri Paulon

\section{Submetido em}

23/03/20.

Aprovado em

20/10/20.

\section{Referências}

1. Organização Mundial da Saúde. Classificação internacional de funcionalidade, incapacidade e saúde. Genebra: OMS; 2001.

2. Diniz D. O que é deficiência. São Paulo: Braziliense; 2007.

3. Denly C. Putting fundamental rights of persons with disabilities on the map [Internet]. Los Angeles: UCLA Fielding School of the Public Health; 2016 [citado 12 Ago 2020]. Disponível em: https://ph.ucla.edu/news/press-release/2016/nov/puttingfundamental-rights-persons-disabilities-map

4. Maciel MRC. Portadores de deficiência: a questão da inclusão social. São Paulo Perspect. 2000; 14(2):51-6.

5. Buscaglia L. Os deficientes e seus pais: um desafio ao aconselhamento. 5a ed. Rio de Janeiro: Record; 2006.

6. Vieira NGB, Mendes NC, Frota LMCP, Frota MA. O cotidiano de mães com crianças portadoras de paralisia cerebral. Rev Bras Promoç Saude. 2008; 21(1):55-60.

7. Montesquieu CLS. O gosto. São Paulo: Iluminuras; 2005. 
8. Coelho T. A cultura como experiência. In: Ribeiro RJ, organizador. Humanidades: um novo curso na USP. São Paulo: Edusp; 2001. p. 65-101.

9. Gallian DMC. A literatura como remédio: os clássicos e a saúde da alma. São Paulo: Martin Claret; 2017.

10. Gallian DMC, Pondé LF, Ruiz R. Humanização, humanismos e humanidades: problematizando conceitos e práticas no contexto da saúde no Brasil. Rev Int Humanidades Med. 2012; 1(1):5-15.

11. Bergson $\mathrm{H}$, organizador. $\mathrm{O}$ pensamento e o movente: ensaios e conferências. São Paulo: Martins Fontes; 2006. p. 149-82.

12. Ricouer P. Tempo e narrativa. São Paulo: Martins Fontes; 2011.

13. Compagnon A. Literatura para quê? Belo Horizonte: Editora UFMG; 2009.

14. Caprara A. Uma abordagem hermenêutica da relação saúde-doença. Cad Saude Publica. 2003; 19(4):923-31.

15. Bittar Y, Sousa MSA, Gallian DMC. A experiência estética da literatura como meio de humanização em saúde: o Laboratório de Humanidades da Escola Paulista de Medicina, Universidade Federal de São Paulo. Interface (Botucatu). 2013; 17(44):171-86.

16. Benedetto MAC, Gallian DMC, Guzman SM, Lima CC. Humanidades e humanização em saúde: a literatura como elemento humanizador para graduandos da área de saúde. Interface (Botucatu). 2014; 18(48):139-50.

17. Valladares L. Os dez mandamentos da observação participante. Rev Bras Cienc Soc. 2007; 22(63):153-5.

18. Fernandes FMB. Considerações metodológicas sobre a técnica da observação participante. In: Mattos RA, Baptista TWF, organizadores. Caminhos para análise das políticas de saúde. Porto Alegre: Rede Unida; 2011. p. 487-503.

19. Meihy JCSB, Holanda F. História oral: como fazer, como pensar. 2a ed. São Paulo: Contexto; 2018.

20. Borkan J. Immersion/crystallization. In: Miller WC, Crabtree BF, organizadores. Doing qualitative research. Thousand Oaks: Sage Publications; 1999. p. 179-94.

21. Moisés M. Dicionário de termos literários. 12a ed. São Paulo: Cultrix; 1974.

22. Amiralian MLTM. O psicólogo e a pessoa com deficiência. In: Masini EAFS, Becker E, Pinto EB, Amaral LA, Kovács MJ, Amiralian MLTM, organizadores. Deficiência: alternativas de intervenção. São Paulo: Casa do Psicólogo; 1997. p. 31-52.

23. Fédida P. A negação da deficiência. In: Davila Neto MI, organizadora. A negação da deficiência: a instituição da diversidade. Rio de Janeiro: Achiamé/Socius; 1984. p. 137-47.

24. Miller NB. Ninguém é perfeito: vivendo e crescendo com crianças que têm necessidades especiais. Campinas: Papirus; 1995. (Educação Especial).

25. Dilthey W. Filosofia e educação: textos selecionados. São Paulo: Edusp; 2010.

26. Sass SD. O método compreensivo na obra de Dilthey. Rev Filos Aurora. 2019; 31(53):536-57.

27. Buber M. Do diálogo e do dialógico. São Paulo: Perspectiva; 2009.

28. Ricouer P. Percurso do reconhecimento. São Paulo: Loyola; 2006.

29. Lévinas E. Entre nós: ensaios sobre a alteridade. 5a ed. Petrópolis: Vozes; 2010. 
This study aims to show the impacts of literature on mothers of people with disabilities, with regard to the reframing of their condition of "special mothers," based on participation in the activities carried out at the Laboratory of Humanities, which is part of the Center for History and Philosophy of Sciences Health, at the Federal University of Sao Paulo, Brazil, whose purposes are to awaken affections and feelings and promote humanization, through the collective discussion of existential themes raised by classic works of universal literature. Three qualitative methodologies were applied after the reading of the fable "Um Apólogo" (An Apologue), by Machado de Assis: LabHum's methodology; Oral Life Story; and Participant Observation. The results indicate positive transformations in perspectives and re-elaboration of humanistic values about the role that these women play as citizens seeking to broaden the debate on the social inclusion of people with disabilities.

Keywords: Disability. Humanization. Laboratory of Humanities. Literature.

El objetivo de este estudio es demostrar los impactos de la literatura en madres de personas con discapacidad, en lo que concierne a la resignificación de la condición de "madres especiales", a partir de su participación en la actividad Laboratorio de Humanidades, del Centro de Historia y Filosofía de las ciencias de la Salud de la Universidad Federal de São Paulo, cuyos propósitos son despertar afectos y sentimientos y fomentar la humanización, por la discusión colectiva de temas existenciales suscitados en los clásicos de la literatura universal. El estudio se desarrolló bajo tres metodologías cualitativas, después de la lectura individualizada de la fábula "Um Apólogo", de Machado de Assis: del propio LabHum, Historia Oral de Vida y Observación Participante. Los resultados indican transformaciones positivas de perspectiva y reelaboración de valores humanísticos sobre el papel que esas mujeres cumplen como ciudadanas que buscan ampliar el debate sobre la inclusión de personas con discapacidad en la sociedad.

Palabras clave: Deficiencia. Humanización. Laboratorio de Humanidades. Literatura. 